\title{
Symposium review: Real-time continuous decision making using big data on dairy farms*
}

\author{
Victor E. Cabrera,† Jorge A. Barrientos-Blanco, Hector Delgado, and Liliana Fadul-Pacheco \\ Department of Dairy Science, University of Wisconsin, Madison, 53706
}

\begin{abstract}
We are developing a real-time, data-integrated, datadriven, continuous decision-making engine, The Dairy Brain, by applying precision farming, big data analytics, and the Internet of Things. This is a transdisciplinary research and extension project that engages multidisciplinary scientists, dairy farmers, and industry professionals. Dairy farms have embraced large and diverse technological innovations such as sensors and robotic systems, and procured vast amounts of constant data streams, but they have not been able to integrate all this information effectively to improve whole-farm decision making. Consequently, the effects of all this new smart dairy farming are not being fully realized. It is imperative to develop a system that can collect, integrate, manage, and analyze on- and off-farm data in real time for practical and relevant actions. We are using the state-of-the-art database management system from the University of Wisconsin-Madison Center for High Throughput Computing to develop our Agricultural Data Hub that connects and analyzes cow and herd data on a permanent basis. This involves cleaning and normalizing the data as well as allowing data retrieval on demand. We illustrate our Dairy Brain concept with 3 practical applications: (1) nutritional grouping that provides a more accurate diet to lactating cows by automatically allocating cows to pens according to their nutritional requirements aggregating and analyzing data streams from management, feed, Dairy Herd Improvement (DHI), and milking parlor records; (2) early risk detection of clinical mastitis (CM) that identifies first-lactation cows under risk of developing $\mathrm{CM}$ by analyzing integrated data from genetic, management, and DHI records; and (3) predicting CM onset that recognizes cows at higher risk of contracting $\mathrm{CM}$,
\end{abstract}

Received June 23, 2019.

Accepted October 22, 2019.

*Presented as part of the Production, Management, and the Environment Symposium: Advancing Artificial Intelligence on Dairy Farms at the 2019 ADSA Annual Meeting, Cincinnati, Ohio, June 2019.

†Corresponding author: vcabrera@wisc.edu by continuously integrating and analyzing data from management and the milking parlor. We demonstrate with these applications that it is possible to develop integrated continuous decision-support tools that could potentially reduce diet costs by $\$ 99 /$ cow per yr and that it is possible to provide a new dimension for monitoring health events by identifying cows at higher risk of $\mathrm{CM}$ and by detecting $90 \%$ of $\mathrm{CM}$ cases a few milkings before disease onset. We are securely advancing toward our overarching goal of developing our Dairy Brain. This is an ongoing innovative project that is anticipated to transform how dairy farms operate.

Key words: decision-making tools, Dairy Brain, continuous data integration, artificial intelligence, simulation, optimization

\section{INTRODUCTION}

The use of new technologies on the dairy farm, along with the Internet of Things to manage livestock production using the principles and techniques of process engineering, becomes precision livestock farming (Wathes et al., 2008; Bewley and Russell, 2010). Thanks to this revolution, dairy farmers have embraced technological innovations that generate massive permanent data streams. Although animal scientists are part of the Big Data revolution, these new technologies have been evolving so rapidly that it has been difficult for dairy farm managers and animal scientists to overcome the new challenge of taking full advantage of the opportunities that big data streams create (Madrigal, 2012).

When analyzed independently, the disparate data streams are informative and describe many of the activities that take place on a dairy farm (e.g., feeding management decisions, genetic testing, test-day results, milk composition, heat detection). However, when they are integrated, they can generate even more important insights of different situations happening at the farm and improve decision making and farm management (Liberati and Zappavigna, 2009). Data streams that are permanently generated on-farm include data such as milking, feeding, reproduction, and behavior. However, real-time integration of these data to improve whole- 
farm management, leading to data-driven decision making in farming, has proven challenging (Nikkilä et al., 2010; van der Weerdt and de Boer, 2015). Dairy producers use separate software tools to visualize and interpret each of all these data streams and make isolated decisions. It is not surprising that some dairy farms do even have computers dedicated to specific farm software, when all these data streams are interrelated.

Farm management evolves constantly, and goodquality, real-time, integrated data can help herd managers identify feeding and health problems (Arcidiacono et al., 2017; Porto et al., 2015), optimize reproduction (LeRoy et al., 2018), and improve the overall production system (Wathes et al., 2008). With the increasing amount of data available at the farm, there is a critical need to automatically integrate the different data sources within decision-making tools that can provide integrated advice to farmers and lead to more efficient herd management (Tomic et al., 2015). This lack of integration and its subsequent analysis and projection generate different problems, such as delays in optimal actions, increased risk of mistakes and failure, lack of awareness of changing environment, suboptimal use of on- and off-farm resources, narrow vision of opportunities for improvement, and, ultimately, suboptimal profitability and consequently decreased sustainability and resilience. However, all these data generated from new technologies offer an opportunity for development of farm-specific models (O'Grady and O'Hare, 2017) to help in the management decision-making process.

Decision-support tools (DST) and projections that account for biological, economic, and environmental uncertainties inherent to the production system are necessary (Mirando et al., 2012). This is only achieved with real-time, integrated big data analytics (Wolfert et al., 2017), where machine learning techniques and data mining are an option to obtain a deeper understanding of big data (Morota et al.,2018). However, to succeed in this process, it is important to consider quality, heterogeneity, and transformation of the data (Hashem et al., 2015), and, because of these, additional procedures are required.

Adoption of precision farming is increasing rapidly. Results of a survey in the US Midwest showed that $64 \%$ of farmers use at least 1 type of digital technology: $47 \%$ of farmers use smartphones apps for information or decision making; 20 to $25 \%$ use precision farming; and $11 \%$ use livestock sensors and drones (Shutske et al., 2018). The increasing amount of these technologies is leading to an exponential increase in the volume of available data that needs to be managed.

In light of all of these factors, the aim of this manuscript is to describe the development of an integrated real-time agricultural data hub (AgDH) for the dairy farming operation and demonstrate its value of continuously integrating data and applying analytics to them, to improve decision making through the development of real-time continuous DST, referred to as the Dairy Brain. The Dairy Brain serves as an exemplar to demonstrate how multiple data sources can be connected to the $\mathrm{AgDH}$ and how, based on those, it is possible to deliver advanced analytics to generate value and innovate the decision-making process (Figure 1). In the near future, the best herd managers and top decision makers will use continuous, integrated real-time predictive tools to estimate the impact of their decisions. As the decision-making process becomes more complex, we expect that this process will be a mixture of human and computer factors with the help of big data analytics (Wolfert et al., 2017).

\section{DATA COLLECTION}

\section{Development of an Integrated Agricultural Data Hub}

We are collecting on- and off-farm data on a permanent basis from a few farms in Wisconsin. Data are extracted according to the frequency of generation. For instance, on-farm records extracted from farm management, feed monitoring, and milking parlor software are collected daily, whereas off-farm data such as DHI testday data, are extracted monthly. The data being collected include (1) herd management: records of routine and operational activities in the herd, such as reproduction, calvings, health events such as vaccinations, presence of diseases, and treatments; (2) milking system: data recorded during the milking process, including milk volume, milk conductivity, and milking flow; (3) genetics and genomics: records of the pedigrees and DNA of tested animals; (4) DHI: records of monthly test-day visit variables, such as milk volume, SCC, milk fat and protein content, total amount of fat and protein in the current lactation, and categorized herd population; (5) feed: records related to the nutrition of the animals, individually or grouped by pens, including diet composition, average consumption per day, DMI, and cost per kilogram of ration; (6) milk processor: records of the milk composition in each milk shipping load, such as milk fat and protein content and SCC. Our intent is to access and integrate all data that are available to the farmer. We anticipate that our $\mathrm{AgDH}$ will continue growing and become a big data hub for the dairy industry when we include more data streams and more farms. The Dairy Brain team understands this challenge and is well positioned to address it. Not all data listed above are used in this paper's demonstration applications. 


\section{Extraction, Transformation, and Loading}

An extraction, transformation, and loading (ETL) process that prepares data for access via a programmatic interface was developed. The process of extraction of the data is secured and firewalled to form a one-way communication channel from the farm to the University of Wisconsin-Madison. Once the data reaches the university, it is immediately stored, archived, dated, and versioned by the Center for High Throughput Computing (HTCondor server, http://chtc.cs.wisc.edu) at the University of Wisconsin-Madison.

Data collected from cooperating farms are stored on university servers. As such, the process involves an ETL process that sets the data for access via a programmatic interface. This ETL process is managed by an automation framework, which runs on the server in the background, monitoring specified directories. A dedicated computer installed on cooperating farms places farm files into specific directories on the server, whose structure is determined by the data source (i.e., which farm, which data source, and which date). The framework identifies the arrival of a new set of data files and, based on the directory structure, implements a predetermined "recipe" of 1 or more programs to extract the information from those files. The process of integrating the data begins with extracting the realtime data from the original file format obtained from the source file. Data are then transformed through a process of cleaning, with data-mining and language- processing tool scripts, which detect and correct or remove corrupt or inaccurate information. The cleaned data are then harmonized, which involves creating, loading, and utilizing a Microsoft SQL relational database (Microsoft Corp., Redmond, WA) as a data warehouse, with common key variables to query the data (Figure 2 ), and a consistent format and structure regardless of the source. As mentioned by Tomic et al. (2015) and Schuetz et al. (2018), this process provides common keys to query the data (e.g., all relevant data sources about a single cow are linked by a single cow identification number), and a consistent format and structure regardless of the source, so that data from one milking parlor software resembles another. The process of data cleaning, integration, and transformation are a key part of the data processing phase (Sayad et al., 2015; Biradar and Shabadi, 2017). Further specific cleaning needs are implemented, depending on the purpose of the data - for example, deleting duplicated records for health events. If a health event such as clinical mastitis (CM) was recorded during 2 or more consecutive days, up to a week, it refers to the same CM case, and then only the first recorded event is considered as a case of $\mathrm{CM}$, and the other or others are considered duplicates (Guard, 2008).

The cleaned and harmonized data are then loaded into a data warehouse, which serves as the $\mathrm{AgDH}$. Therefore, the integrated data could be extracted for visualization or analyses. An important aspect to consider is matching different data dimensions. For

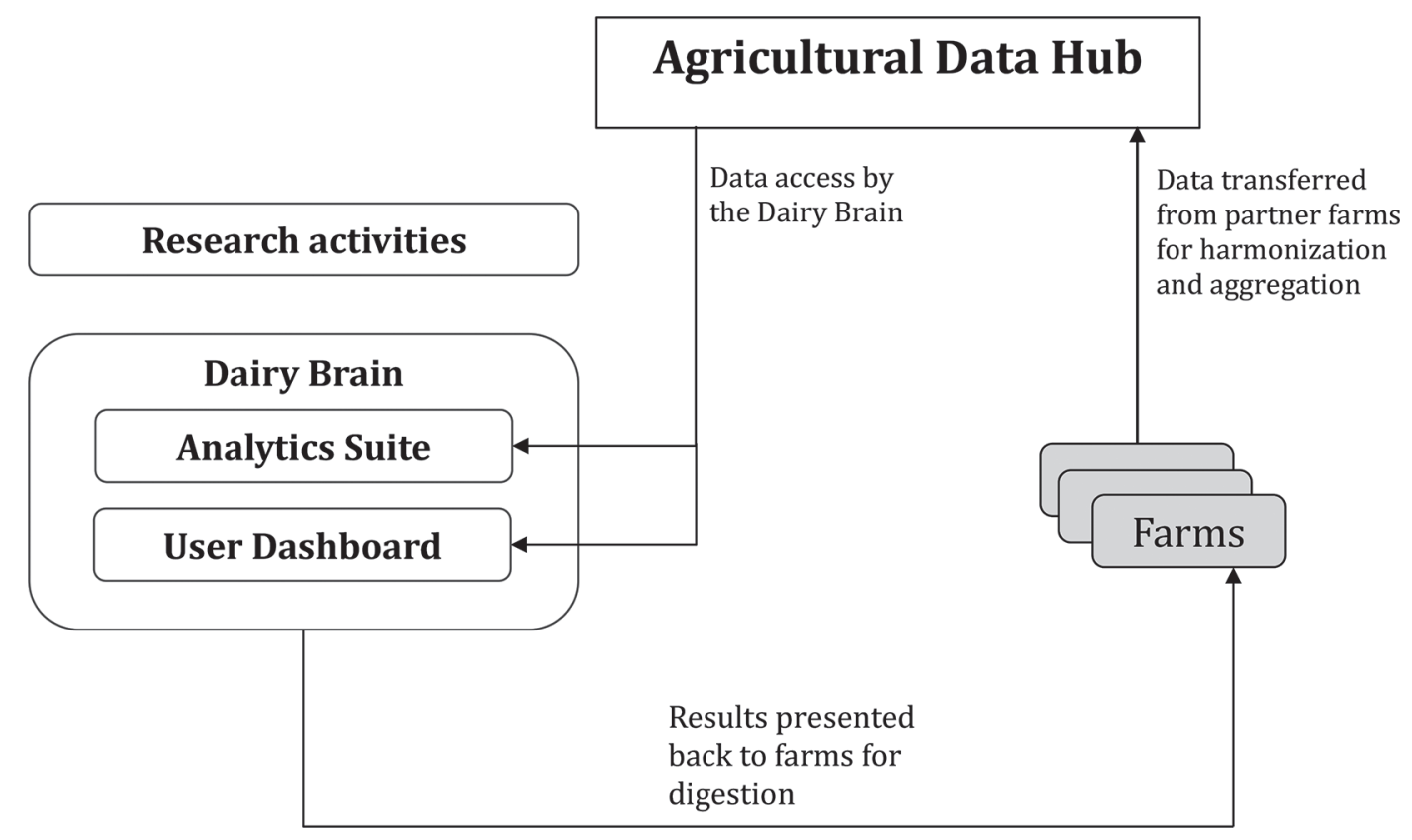

Figure 1. Relational schema of data streams extracted from the different software and services included in the database. 


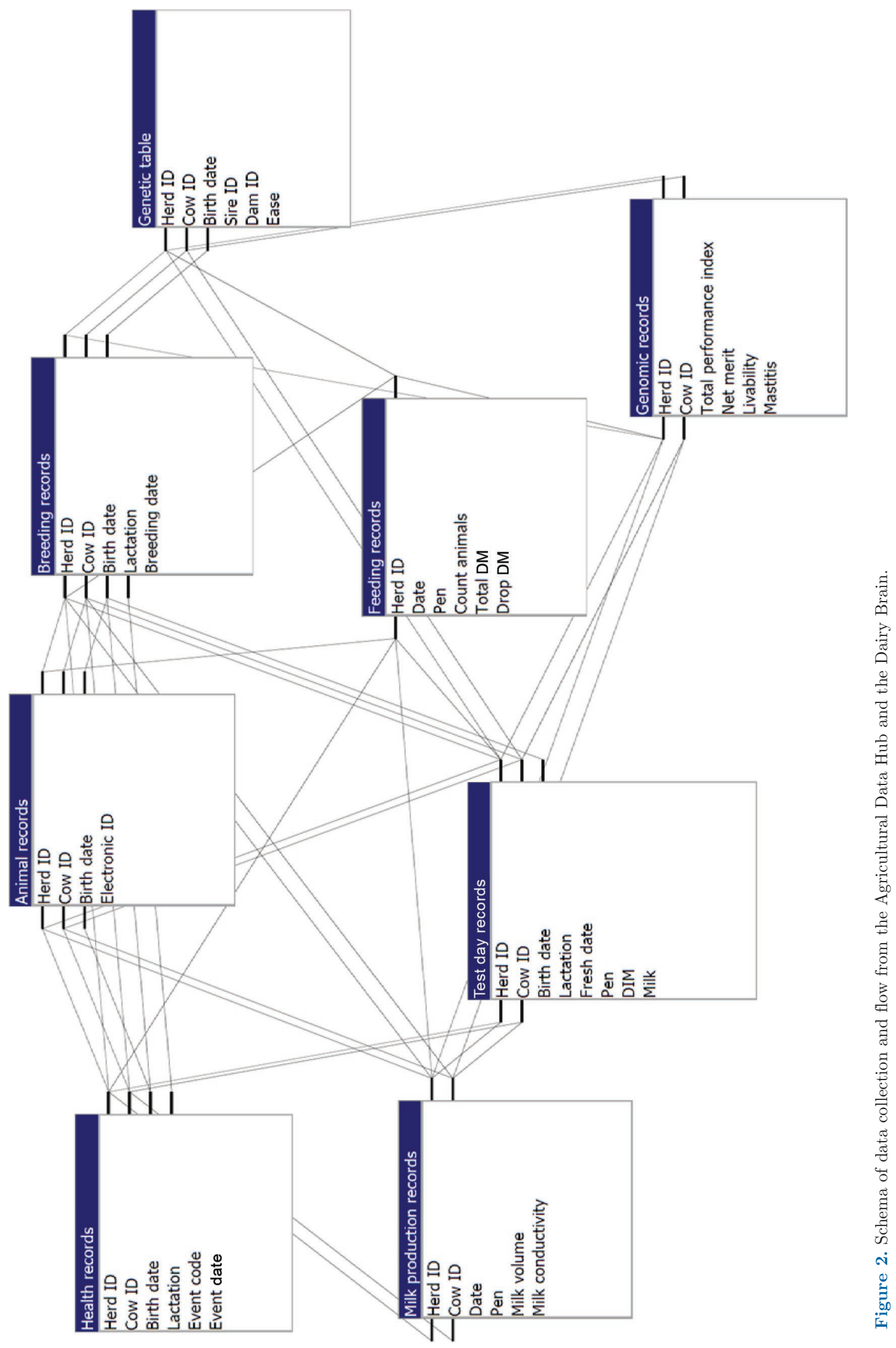


instance, the feed monitoring system keeps records of the diets supplied to a group of animals (pen-level); however, it does not record individual cow-level feeding. Consequently, an individual cow's feed intake can only be approximated as the average consumption of the pen. For such calculation, the cow's pen allocation by date is needed, which is extracted from the management software.

Based on the known farm configuration and the associated vendor for the data source, the main body of the program uses a separately developed module that contains the data-parsing logic specific to that software vendor. This approach facilitates the addition or replacement of a new vendor to a data source, through the addition or replacement of a new module file, and reduces the amount of changes or duplication of the code within the main process. This approach is used to extract data reflecting the milk production, feed ration composition and quantities, and events reflecting the health or management of individual cows. These data sources are going to dynamically grow to reach big data status as more farms with new and different technologies and software are added.

\section{REAL-TIME PRACTICAL APPLICATIONS UNDER DEVELOPMENT}

The vision for the Dairy Brain is a real-time analytical engine capable of performing longitudinal historical analyses and forecasting future from past information in a continuous loop. This is a working task in progress. Here, we prove our concept, with 3 DST as exemplars that demonstrate the feasibility and value added of continuous application of integrated real-time data (Table 1).

\section{(1) Continuous Nutritional Grouping}

Nutritional grouping ( $\mathbf{N G}$ ) is a potentially effective strategy to control cost and enhance efficiency and productivity in dairy farms. This strategy consists of aggregating lactating cows in groups with more homogeneous nutritional requirements (St-Pierre and Thraen, 1999; Cabrera et al., 2012; Cabrera and Kalantari, 2016). Even though multiple studies have demonstrated economic and productive benefits of NG strategies (Bach, 2014; Kalantari et al., 2016; Wu et al., 2019), dairy farmers are still skeptical of adopting them. Among other things, they have concerns about adding management complexity to the grouping management and decreasing milk yield when moving cows to a different group (Contreras-Govea et al., 2015). Nevertheless, current available data, computer systems, feeding systems, and already-existing cow grouping practices used on dairy farms open the opportunity for developing models and tools that facilitate the implementation of NG strategies.

To systematize grouping management, improve the efficiency and precision of grouping management, and facilitate implementation of NG strategy, we have developed an application tool. The model was designed to (1) continuously integrate live data streams from the milking, feeding, and management software, and from DHI, available through our $\mathrm{AgDH}$; (2) group cows according to their lactation (first lactation, greater than first lactation), stage of lactation (fresh, early, peak, or late lactation), milk yield, and $\mathrm{MP}$ and $\mathrm{NE}_{\mathrm{L}}$ requirements; (3) provide a list of cows for each nutritional group; and (4) calculate the $\mathrm{NE}_{\mathrm{L}}$ and $\mathrm{MP}$ requirements of cows in a group to formulate the group diet.

We included all healthy lactating cows for a case study of a Wisconsin farm ( $\mathrm{n}=1,898 \pm 115$ animals) that currently regroups lactating cows weekly in 14 pens according to lactation number and stage [farm grouping (FG)], for which 9 diets are provided. We followed this farm's current practices but added $\mathrm{NE}_{\mathrm{L}}$, $\mathrm{MP}$, and milk yield as criteria for regrouping cows distributed in different pens but in the same stage (pens 7, 8, and 9; 22, 23, and 24; and 2,3,4, and 6 in Table 2 ). As expected, our NG model showed better consis-

Table 1. Summary of models and decision support tools developed for continuous decision making with real-time integrated data

\begin{tabular}{llll}
\hline Model/tool & Algorithm & Live data sources & Benefits \\
\hline Nutritional grouping & Cluster & Management & Milking parlor \\
& & $\begin{array}{l}\text { Increase nutritional accuracy } \\
\text { Decrease feed costs }\end{array}$ \\
& & Feed monitoring & \\
Early risk of clinical mastitis & Stepwise & Management & Identify first-lactation cows at high risk of \\
& Logistic regression & Health events & developing clinical mastitis \\
& Naive Bayes & Genomics & \\
Early prediction of clinical mastitis & Gradient boosting & Management & Identify cows at risk of clinical mastitis 5 \\
& & Health events & milkings before disease onset \\
\hline
\end{tabular}


tency in assigning lactating cows to groups by removing potential errors from assigning cows to incorrect pens. Importantly, the implementation of the NG model created more homogeneous groups of cows in terms of milk yield and $\mathrm{NE}_{\mathrm{L}}$ and $\mathrm{MP}$ density requirements. An illustration that contrasts the $\mathrm{NE}_{\mathrm{L}}$ and $\mathrm{MP}$ requirements, DIM, milk yield, and diet costs, either using current FG strategy or our proposed NG strategy, is shown in Table 2. For example, the NG for peak-lactation animals shows more hierarchical distribution of DIM, $\mathrm{NE}_{\mathrm{L}}$, and MP requirements and milk yield within groups than does the FG for peak-lactation animals (Table 2), which results in better nutrient allocation and therefore higher nutritional accuracy of the diets (Kalantari et al., 2016; Barrientos et al., 2018; Bach, 2019). Better nutritional accuracy decreases the incidence of over- or underconditioned cows and increases milk productivity (Allen, 2009; Maltz et al., 2013; Kalantari et al., 2016). Better nutritional accuracy resulted in $15.5 \mathrm{~kg} /$ cow per yr lower $\mathrm{N}$ waste and $\$ 99 /$ cow per yr greater net return due to diet cost savings. Note that the difference in diet cost between FG and NG was not always positive (Table 2), meaning that, for some groups, the FG diet was less expensive than the NG diet. This was an expected outcome, explained by the different flow of cows under stricter grouping criteria with our NG. Nonetheless, the important outcome to note is that the overall herd income over feed cost (IOFC) resulted in a substantially higher value with our proposed grouping strategy.

\section{(2) Permanent Assessment of Early Risk of Clinical Mastitis}

Although significant research has been done about prevention and treatment of $\mathrm{CM}$, the presence of $\mathrm{CM}$ still has an important negative effect on dairy farm profitability (Delgado et al., 2017). The average cost of a CM case varies between $\$ 325.76 \pm 71.12( \pm \mathrm{SD}$; Liang et al., 2017) and $\$ 426.50 \pm 80.27$ (Rollin et al., 2015). It is also documented that CM shortens the life spans of dairy cows because of a significant increase in the risk of culling (Heikkilä et al., 2012). In most intensive dairy production systems in Europe and North America, CM, along with reproductive and foot and leg problems, are the most important causes of involuntary culling (Bascom and Young, 1998; Bar et al., 2008; Rushen and de Passillé, 2013). Farmers will greatly benefit from systems that can identify cows at higher risk of contracting CM.

We demonstrate a continuous analysis to identify firstlactation cows with higher risk of CM (1stLactCM) using integrated data from genomic, management, and DHI records, collected by our AgDH. Our case study

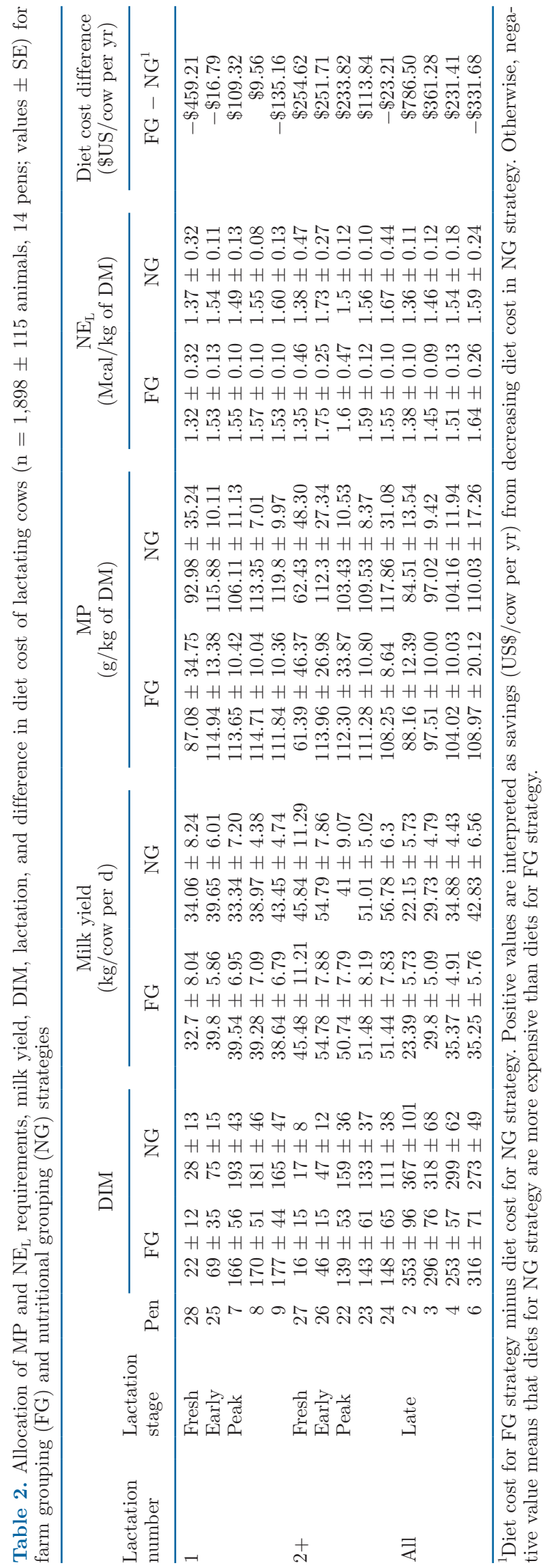

Journal of Dairy Science Vol. 103 No. 4, 2020 
Table 3. Odds ratio estimates for clinical mastitis in first-lactation cows for 7 genomic-based PTA traits, comparing the $25 \%$ of the animals with the lowest values with the $25 \%$ with the highest values

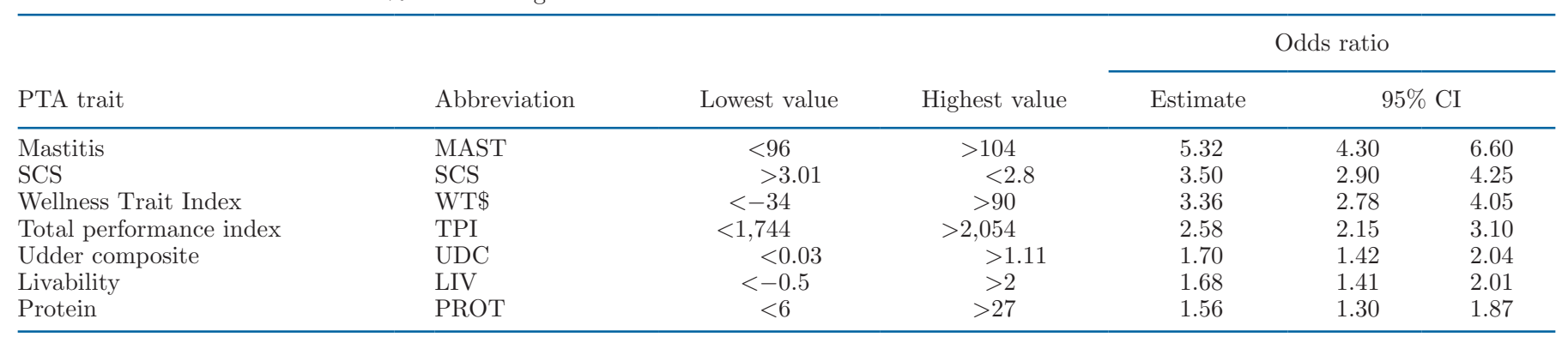

included records from 5,756 first-lactation genomically tested cows from 2 Wisconsin herds between the years 2014 and 2018. From the total records, 1,179 first-lactation cows presented at least 1 case of $\mathrm{CM}$ between the first and tenth test times (between 10 and 320 DIM).

A vector indicating the presence or absence of 1stLactCM was regressed on 14 genomic-based PTA traits: net merit, cheese merit, fluid merit, total performance index, fat, protein, SCS, productive life, udder composite, BW composite, livability, dairy wellness profit, wellness trait index, and Zoetis mastitis (MAST). A stepwise logistic regression model was used to identify significant variations $(P<0.05)$. Seven PTA (SCS, MAST, wellness trait index, udder composite, protein, productive life, and total performance index) were associated with higher risk of 1stLactCM. For example, animals with a MAST value $<96$ had a 5.3 times higher chance of developing 1stLactCM than did animals with a MAST value $>104(P<0.0001$; Table 3).

The identified significant PTA traits - together with SCC, $\log$ SCC scores from test day, and presence or absence of ketosis, retained placenta, metritis, and abortion - were used to identify animals at risk of 1stLactCM using naïve Bayes (Rish, 2001) and random forest (Breiman, 2001) machine learning techniques. A 10 -fold cross-validation was used to compute the results. As described by Kamphuis et al. (2010a), The 10 -fold cross-validation randomly creates 10 folds with approximately the same distribution for positive and negative cases of mastitis, and each fold is used for testing ( $1 / 10$ of the data), while the remainder $(9 / 10)$ are used for training. The threshold used by the algorithms to classify a cow under risk of mastitis was 0.50. The performance of the algorithms was measured using receiver operating characteristic and area under the curve, comparing true positive versus false positive rates.

The naïve Bayes algorithm correctly classified $50 \%$ of the true positive cases and $78 \%$ of the true negative cases, with an overall accuracy of $74.1 \%$ during early lactation (DIM $<$ 90, 3 test-day records). These results did not improve after including a new test result (DIM $<120,4$ test-day records). Results, however, improved drastically using the random forest algorithm and including 4 test-day results (DIM $<120)$. The random forest algorithm properly classified $78 \%$ of the true positive cases and $95 \%$ of the true negative cases, with an overall accuracy of $95.5 \%$. This is explained in part because of the significant effects of variations in the SCC results compared with previous test-day results (Steeneveld et al., 2008). Our results followed the trajectory of previous reports with respect to using machine learning to identify mastitis cases. Cavero et al. (2008), using neural networks and data from automated milking systems, correctly identified between $51.3 \%$ and $80.5 \%$ of mastitis cases. Later, Sun et al. (2010), using the same methodology, reported results that reached a true positive rate of $87 \%$. More recently, Ebrahimie et al. (2018), using a decision tree random forest algorithm, reported accuracy of $90 \%$.

Integration of permanent data can provide a new dimension in monitoring cows at risk of 1stLactCM. Anticipation of what could potentially happen with an animal in the future, according to genetics, health conditions, reproductive status, and historical events, is of utmost importance for optimal dairy farm management. Our results are encouraging. Moreover, we are confident that the inclusion of new data and setting up a continuous process of data integration and analysis will substantially improve prediction abilities.

\section{(3) Continuous Prediction of Onset of Clinical Mastitis}

The continuous integration of different data sources could improve the predictive performance of CM models compared with models that use only 1 data stream source (Hogeveen et al., 2010). Consequently, we developed a model that aims to predict the onset of $\mathrm{CM}$ using data from the milking system (milk production, $\mathrm{kg}$; milk conductivity, $\mathrm{mS} / \mathrm{cm}$ ) and data from manage- 
ment (CM, metritis, and retained placenta cases, with previous cases as categorical variables, lactation, and DIM). For this analysis, DIM were limited to 1 to 150 , and lactations were grouped as 1,2 , and $3+$. One of the limitations of $\mathrm{CM}$ prediction is the low prevalence of CM (Hogeveen et al., 2010; Kamphuis et al., 2010b), which in our case accounted for only 1\% (981 cases) of the total records used. Therefore, it was necessary to balance the data. The synthetic minority over-sampling technique (SMOTE; Chawla et al., 2002) was used for balancing the data. This technique consists of an oversampling approach of the minority class, considering the $k$-nearest neighbor to synthetically create additional observations for this class. With the resulting data, various classifications of machine learning algorithms were tested, using $75 \%$ of the data as training data, and models were trained using 10-fold cross-validation with 3 iterations. Predictor variables were the difference of milk production and milk conductivity between milkings, lactation groups, DIM, and previous cases of CM, retained placenta, and metritis. Variables were selected according to the VarImp function of the caret package (Kuhn, 2008) in R version 3.5.3 (R Foundation for Statistical Computing, Vienna, Austria). Only variables with a variable importance value greater than 0 were retained. Variables retained were the differences in milk production and milk conductivity between milkings, lactation groups, and DIM. Our results showed that the Gradient Boosting algorithm of the caret package (Kuhn, 2008) had the best performance. Also, best results were achieved using data from the 5 previous milkings before the reported case of CM. The Gradient Boosting had a specificity of $61 \%$ and a sensitivity of $71 \%$, with an overall accuracy of $71 \%$ when the model was adjusted according to the receiver operating characteristics curve. Similar results of $75 \%$ sensitivity and $80 \%$ specificity have been reported from a neural network and generalized additive models (Ankinakatte et al., 2013). However, results from other studies using decision-tree models showed that, although specificity was maintained at $99 \%$, the sensitivity varied widely, ranging between 13.3 and $71.4 \%$ (Kamphuis et al., 2010b). Differences between results can be explained by the different conditions of the studies, such as types of milking systems, variables used, or time frame.

Differences in milk conductivity and milk production between healthy and CM cows were analyzed using ANOVA and Tukey honest significant difference tests. Cows with CM had higher absolute mean differences of milk conductivity (0.92 vs. $0.86 \mathrm{mS} / \mathrm{cm} ; P<0.001$ ) and milk production (2.22 vs. $1.95 \mathrm{~kg} ; P<0.001)$ than healthy cows. Even though results from milk conductivity to detect $\mathrm{CM}$ are not consistent, studies report significant increases of milk conductivity in cows with CM compared with healthy cows (Norberg et al., 2004; Norberg, 2005; King et al., 2018). On the other hand, studies have also reported that milk losses are related to the type of pathogen, such that reduction of milk yield was seen 1 wk before diagnosis of CM from Streptococcus spp. and Staphylococcus aureus, whereas for other pathogens milk losses occurred several weeks following the diagnosis or did not occur at all (Gröhn et al., 2004; Hertl et al., 2014). Gröhn et al. (2004), Hertl et al. (2014), and Rajala-Schultz et al. (1999) reported, in agreement with our findings, that, in general, CM cows had higher milk production than did healthy cows before the onset of CM. In our results, milk production of healthy cows was $0.80 \mathrm{~kg} / \mathrm{d}$ lower than $\mathrm{CM}$ cows, which is within the range of 0.7 to $1.9 \mathrm{~kg} / \mathrm{d}$ reported by Rajala-Schultz et al. (1999).

Our algorithm generates a list of cows at risk of CM for which a close follow-up can be implemented and actionable decisions can be made according to the farm's health protocols and the cow's evolution. As suggested by Kamphuis et al. (2010b), it is useful to have a herd-specific model in which the final users can vary thresholds according to farm risk preferences. In classification models, the threshold (or cut-off probability) is a choice beyond which the variable of interest is classified as present (Freeman and Moisen, 2008). Generally, a threshold of 0.5 is set as the cut-off, but it can be adjusted for detecting more true positives or minimizing false alerts (Claycomb et al., 2009). Therefore, the farmer can choose between having a higher detection rate (with more false-positive cases) or a lower detection rate (with fewer false-positive cases) according to farm's goals and CM prevalence (Table 4). For example, a threshold change from 0.5 to 0.4 in the algorithm could mean for farm A, with a $0.7 \% \mathrm{CM}$ prevalence, an increase in sensitivity from 63 to $81 \%$ and a decrease of specificity from 67 to $48 \%$. This change would reduce the CM detection rate by $4.8 \%$ but would also reduce false positive alerts by $4.5 \%$ (Table 4 ). For farm B, with a $1.1 \% \mathrm{CM}$ prevalence, the same change could mean an increase of sensitivity from 66 to $88 \%$ and a decrease in specificity from 62 to $27 \%$. This change would reduce the $\mathrm{CM}$ detection rate by $9 \%$ but would also reduce false positive alerts by $5.5 \%$ (Table 4 ).

We anticipate this process to be continuous, dynamic, and interactive, which means that the prediction accuracy will improve as more data and more integrated live data streams become available. Similar to the process in which farmers gain experience and expertise over time, we expect that the prediction and DST will learn as it goes, so projections, and consequently decisions, will improve over time. 
Table 4. Sensitivity, specificity, and accuracy of the Gradient Boosting algorithm, according to farm clinical mastitis (CM) prevalence with different thresholds (cut-off probability beyond which a CM case is classified as such) ${ }^{1}$

\begin{tabular}{|c|c|c|c|c|c|c|}
\hline \multirow[b]{2}{*}{ Threshold } & \multicolumn{3}{|c|}{ Farm A CM prevalence $=0.7 \%$} & \multicolumn{3}{|c|}{ Farm B CM prevalence $=1.1 \%$} \\
\hline & $\begin{array}{c}\text { Sensitivity } \\
(\%)\end{array}$ & $\begin{array}{c}\text { Specificity } \\
(\%)\end{array}$ & $\begin{array}{c}\text { Accuracy } \\
(\%)\end{array}$ & $\begin{array}{c}\text { Sensitivity } \\
(\%)\end{array}$ & $\begin{array}{c}\text { Specificity } \\
(\%)\end{array}$ & $\begin{array}{c}\text { Accuracy } \\
(\%)\end{array}$ \\
\hline 0.4 & 81 & 48 & 81 & 88 & 27 & 87 \\
\hline 0.45 & 71 & 56 & 71 & 76 & 48 & 76 \\
\hline 0.5 & 63 & 67 & 63 & 66 & 62 & 66 \\
\hline 0.55 & 59 & 75 & 59 & 53 & 79 & 54 \\
\hline
\end{tabular}

${ }^{1}$ To illustrate of the effect of CM prevalence and defined threshold on the Gradient Boosting algorithm accuracy, 2 data extractions that resulted in 2 levels of $\mathrm{CM}$ prevalence $(0.7$ and $1.1 \%)$ were used in combination with different threshold levels $(0.4,0.45,0.5,0.55$, and 0.6$)$.

\section{CONCLUSIONS}

We are successfully implementing a real-time, dataintegrated, data-driven, continuous decision-making engine: The Dairy Brain. Our framework includes an $\mathrm{AgDH}$ that connects cow, herd, and farm live data streams. We demonstrate our concept with 3 practical dairy farm applications, which show the potential to support advanced data analytics using data integration and real-time predictive tools to improve farm management decision making. Using combined herd management and feeding data sets, we could improve nutritional accuracy and feed efficiency, decreasing feed costs and nutrient losses. Using combined health and genomic data, we could identify cows at higher risk of contracting CM during first lactation, and using combined health, management, and milking parlor data, we could identify cows at risk of contracting CM before onset of the disease. We are securely advancing to our overarching goal of developing our Dairy Brain. This effort could support a paradigm change in how dairy farms manage their farms and make decisions in the short, medium, and long terms, to meet operational, tactical, and strategic goals.

\section{ACKNOWLEDGMENTS}

This project is supported by the University of Wisconsin-Madison UW2020 initiative that encourages highly innovative and groundbreaking research. This project is also supported by USDA-NIFA-FACT grant 2019-68017-29935 (Washington, DC). The authors thank Adam Christensen and Steve Wangen, Wisconsin Institute for Discovery; Michael Ferris, Miron Livny, and Jignesh Patel, Computer Sciences Department; and Kent Weigel and Heather White, Dairy Science Department (all of the University of Wisconsin-Madison), for their contributions to this work as part of the Dairy Brain team. The authors have not stated any conflicts of interest.

\section{REFERENCES}

Allen, M. S. 2009. Grouping to increase milk yield and decrease feed costs. Pages $61-65$ in Proc. Tri-State Dairy Nutr. Conf., Ft. Wayne, The Ohio State University, Columbus.

Ankinakatte, S., E. Norberg, P. Løvendahl, D. Edwards, and S. Højsgaard. 2013. Predicting mastitis in dairy cows using neural networks and generalized additive models: A comparison. Comput. Electron. Agric. 99:1-6. https://doi.org/10.1016/j.compag.2013.08 .024 .

Arcidiacono, C., S. M. C. Porto, M. Mancino, and G. Cascone. 2017. Development of a threshold-based classifier for real-time recognition of cow feeding and standing behavioural activities from accelerometer data. Comput. Electron. Agric. 134:124-134. https:// doi.org/10.1016/j.compag.2017.01.021.

Bach, A. 2014. Precision feeding to increase efficiency for milk production. West. Can. Dairy Semin. Adv. Dairy Technol. 26:177-189.

Bach, A. 2019. Decomposing efficiency of milk production and maximizing profit. J. Dairy Sci. 102(Suppl. 1):397 (Abstr.).

Bar, D., Y. T. Gröhn, G. Bennett, R. N. González, J. A. Hertl, H. F. Schulte, L. W. Tauer, F. L. Welcome, and Y. H. Schukken. 2008. Effects of repeated episodes of generic clinical mastitis on mortality and culling in dairy cows. J. Dairy Sci. 91:2196-2204. https:// doi.org/10.3168/jds.2007-0460.

Barrientos, J. A., E. Chabonneau, S. Binggeli, and V. E. Cabrera. 2018. Improving nutritional accuracy and economics through multiple ration-grouping strategy. Pages 1-58 in Proc. Symposium sur les bovins laitiers, Drummondville, Québec, Canada. Centre de Référence en Agriculture et Agroalimentaire du Québec, Québec, Canada.

Bascom, S. S., and A. J. Young. 1998. A summary of the reasons why farmers cull cows. J. Dairy Sci. 81:2299-2305. https://doi.org/10 $.3168 /$ jds.S0022-0302(98)75810-2.

Bewley, J. M., and R. A. Russell. 2010. Reasons for slow adoption rates of precision dairy farming technologies: Evidence from a producer survey. Pages 30-31 in Proc. First North Amer. Conf. Precision Dairy Management, Toronto, Canada. Accessed Oct. 1, 2019. http://www.precisiondairy.com/proceedings/s1bewley2.pdf.

Biradar, H. B., and L. Shabadi. 2017. Review on IOT based multidisciplinary models for smart farming. Pages 1923-1926 in Proc. 2nd IEEE International Conference on Recent Trends in Electronics, Information \& Communication Technology (RTEICT), Bengaluru, India. IEEE, New York, NY.

Breiman, L. 2001. Random forests. Mach. Learn. 45:5-32. https://doi .org/10.1023/A:1010933404324.

Cabrera, V. E., F. Contreras, R. D. Shaver, and L. Armentano. 2012. Grouping strategies for feeding lactating dairy cattle. Pages 13-14 in Proc. Four-State Dairy Nutrition and Management Conference, Dubuque, IA. Wisconsin Agri-business Association, Madison.

Cabrera, V. E., and A. S. Kalantari. 2016. Economics of production efficiency: Nutritional grouping of the lactating cow. J. Dairy Sci. 99:825-841. https://doi.org/10.3168/jds.2015-9846. 
Cavero, D., K. H. Tölle, C. Henze, C. Buxadé, and J. Krieter. 2008. Mastitis detection in dairy cows by application of neural networks. Livest. Sci. 114:280-286. https://doi.org/10.1016/j.livsci.2007.05 .012 .

Chawla, N. V., K. W. Bowyer, L. O. Hall, and W. P. Kegelmeyer. 2002. SMOTE: Synthetic minority over-sampling technique. J. Artif. Intell. Res. 16:321-357. https://doi.org/10.1613/jair.953.

Claycomb, R. W., P. T. Johnstone, G. A. Mein, and R. A. Sherlock. 2009. An automated in-line clinical mastitis detection system using measurement of conductivity from foremilk of individual udder quarters. N. Z. Vet. J. 57:208-214. https://doi.org/10.1080/ 00480169.2009.36903.

Contreras-Govea, F. E., V. E. Cabrera, L. E. Armentano, R. D. Shaver, P. M. Crump, D. K. Beede, and M. J. VandeHaar. 2015. Constraints for nutritional grouping in Wisconsin and Michigan dairy farms. J. Dairy Sci. 98:1336-1344. https://doi.org/10.3168/ jds.2014-8368.

Delgado, H., R. Cue, D. Haine, A. Sewalem, R. Lacroix, D. Lefebvre, J. Dubuc, E. Bouchard, and K. M. Wade. 2017. Profitability measures as decision-making tools for Québec dairy herds. Can. J. Anim. Sci. CJAS-2016-0202. https://doi.org/10.1139/CJAS-2016 $-0202$.

Ebrahimie, E., F. Ebrahimi, M. Ebrahimi, S. Tomlinson, and K. R. Petrovski. 2018. Hierarchical pattern recognition in milking parameters predicts mastitis prevalence. Comput. Electron. Agric. 147:6-11. https://doi.org/10.1016/j.compag.2018.02.003.

Freeman, E. A., and G. G. Moisen. 2008. A comparison of the performance of threshold criteria for binary classification in terms of predicted prevalence and kappa. Ecol. Modell. 217:48-58. https:// doi.org/10.1016/j.ecolmodel.2008.05.015.

Gröhn, Y. T., D. J. Wilson, R. N. González, J. A. Hertl, H. Schulte, G. Bennett, and Y. H. Schukken. 2004. Effect of pathogen-specific clinical mastitis on milk yield in dairy cows. J. Dairy Sci. 87:33583374. https://doi.org/10.3168/jds.S0022-0302(04)73472-4.

Guard, C. 2008. The costs of common diseases of dairy cattle. Pages 695-700 in Proc. Calif. Vet. Conf., San Diego, CA. Advanstar Communications, Lenexa, KS.

Hashem, I. A. T., I. Yaqoob, N. B. Anuar, S. Mokhtar, A. Gani, and S. Ullah Khan. 2015. The rise of "big data" on cloud computing: Review and open research issues. Inf. Syst. 47:98-115. https://doi .org/10.1016/j.is.2014.07.006.

Heikkilä, A. M., J. I. Nousiainen, and S. Pyörälä. 2012. Costs of clinical mastitis with special reference to premature culling. J. Dairy Sci. 95:139-150. https://doi.org/10.3168/jds.2011-4321.

Hertl, J. A., Y. H. Schukken, F. L. Welcome, L. W. Tauer, and Y. T Gröhn. 2014. Pathogen-specific effects on milk yield in repeated clinical mastitis episodes in Holstein dairy cows. J. Dairy Sci. 97:1465-1480. https://doi.org/10.3168/jds.2013-7266.

Hogeveen, H., C. Kamphuis, W. Steeneveld, and H. Mollenhorst. 2010. Sensors and clinical mastitis - The quest for the perfect alert. Sensors (Basel) 10:7991-8009. https://doi.org/10.3390/s100907991.

Kalantari, A. S., L. E. Armentano, R. D. Shaver, and V. E. Cabrera. 2016. Economic impact of nutritional grouping in dairy herds. J. Dairy Sci. 99:1672-1692. https://doi.org/10.3168/jds.2015-9810.

Kamphuis, C., H. Mollenhorst, A. Feelders, D. Pietersma, and H. Hogeveen. 2010a. Decision-tree induction to detect clinical mastitis with automatic milking. Comput. Electron. Agric. 70:60-68. https: //doi.org/10.1016/j.compag.2009.08.012.

Kamphuis, C., H. Mollenhorst, J. A. P. Heesterbeek, and H. Hogeveen. 2010b. Detection of clinical mastitis with sensor data from automatic milking systems is improved by using decision-tree induction. J. Dairy Sci. 93:3616-3627. https://doi.org/10.3168/jds.2010 -3228 .

King, M. T. M., S. J. LeBlanc, E. A. Pajor, T. C. Wright, and T. J. DeVries. 2018. Behavior and productivity of cows milked in automated systems before diagnosis of health disorders in early lactation. J. Dairy Sci. 101:4343-4356. https://doi.org/10.3168/ jds.2017-13686.

Kuhn, M. 2008. Building predictive models in $\mathrm{R}$ using the caret package. J. Stat. Softw. 28:1-26. https://doi.org/10.18637/jss.v028.i05.
LeRoy, C. N. S., J. S. Walton, and S. J. LeBlanc. 2018. Estrous detection intensity and accuracy and optimal timing of insemination with automated activity monitors for dairy cows. J. Dairy Sci. 101:1638-1647. https://doi.org/10.3168/jds.2017-13505.

Liang, D., L. M. Arnold, C. J. Stowe, R. J. Harmon, and J. M. Bewley. 2017. Estimating US dairy clinical disease costs with a stochastic simulation model. J. Dairy Sci. 100:1472-1486. https://doi.org/10 $.3168 /$ jds.2016-11565.

Liberati, P., and P. Zappavigna. 2009. Improving the automated monitoring of dairy cows by integrating various data acquisition systems. Comput. Electron. Agric. 68:62-67. https://doi.org/10 .1016/j.compag.2009.04.004.

Madrigal, A. C. 2012. The perfect milk machine: How big data transformed the dairy industry. The Atlantic. Accessed Nov. 8, 2019. https://www.theatlantic.com/technology/archive/2012/ 05/the-perfect-milkmachine-how-big-data-transformed-the-dairy -industry/256423/

Maltz, E., L. Barbosa, P. Bueno, L. Scagion, K. Kaniyamattam, L. Greco, A. De Vries, and J. Santos. 2013. Effect of feeding according to energy balance on performance, nutrient excretion, and feeding behavior of early lactation dairy cows. J. Dairy Sci. 96:5249-5266. https://doi.org/10.3168/jds.2013-6549.

Mirando, M. A., J. M. Bewley, J. Blue, D. M. Amaral-Phillips, V. A. Corriher, K. M. Whittet, N. Arthur, and D. J. Patterson. 2012. Extension Education Symposium: Reinventing extension as a resource - What does the future hold? J. Anim. Sci. 90:3677-3692. https://doi.org/10.2527/jas.2011-5074.

Morota, G., R. V. Ventura, F. F. Silva, M. Koyama, and S. C. Fernando. 2018. Big Data Analytics and Precision Animal Agriculture Symposium: Machine learning and data mining advance predictive big data analysis in precision animal agriculture. J. Anim. Sci. 96:1540-1550. https://doi.org/10.1093/jas/sky014.

Nikkilä, R., I. Seilonen, and K. Koskinen. 2010. Software architecture for farm management information systems in precision agriculture. Comput. Electron. Agric. 70:328-336. https://doi.org/10.1016/j .compag.2009.08.013.

Norberg, E. 2005. Electrical conductivity of milk as a phenotypic and genetic indicator of bovine mastitis: A review. Livest. Prod. Sci. 96:129-139. https://doi.org/10.1016/j.livprodsci.2004.12.014.

Norberg, E., H. Hogeveen, I. R. Korsgaard, N. C. Friggens, K. H. M. N. Sloth, and P. Løvendahl. 2004. Electrical conductivity of milk: Ability to predict mastitis status. J. Dairy Sci. 87:1099-1107. https://doi.org/10.3168/jds.S0022-0302(04)73256-7.

O'Grady, M. J., and G. M. P. O'Hare. 2017. Modelling the smart farm. Inf. Process. Agric. 4:179-187. https://doi.org/10.1016/j inpa.2017.05.001.

Porto, S. M. C., C. Arcidiacono, U. Anguzza, and G. Cascone. 2015. The automatic detection of dairy cow feeding and standing behaviours in free-stall barns by a computer vision-based system. Biosyst. Eng. 133:46-55. https://doi.org/10.1016/j.biosystemseng .2015.02.012.

Rajala-Schultz, P. J., Y. T. Gröhn, C. E. McCulloch, and C. L. Guard. 1999. Effects of clinical mastitis on milk yield in dairy cows. J. Dairy Sci. 82:1213-1220. https://doi.org/10.3168/jds.S0022 $-0302(99) 75344-0$.

Rish, I. 2001. An empirical study of the naive Bayes classifier. In IJCAI 2001 workshop on empirical methods in artificial intelligence, 3(22):41-46.

Rollin, E., K. C. Dhuyvetter, and M. W. Overton. 2015. The cost of clinical mastitis in the first 30 days of lactation: An economic modeling tool. Prev. Vet. Med. 122:257-264. https://doi.org/10.1016/j .prevetmed.2015.11.006.

Rushen, J., and A. M. de Passillé. 2013. The importance of improving cow longevity. Pages 28-29 in Proc. Cow Longevity Conference, Tumba, Sweden. DeLaval International, Tumba, Sweden.

Sayad, Y. O., H. Mousannif, and M. Le Page. 2015. Crop management using Big Data. Pages 1-6 in International Conference on Cloud Technologies and Applications (CloudTech), Marrakech, Morocco. IEEE, New York City, NY. 
Schuetz, C. G., S. Schausberger, and M. Schrefl. 2018. Building an active semantic data warehouse for precision dairy farming. J. Organ. Comput. Electron. Commerce 28:122-141. https://doi.org/10 $.1080 / 10919392.2018 .1444344$.

Shutske, J. M., D. Trechter, B. D. Luck, J. L. Drewry, M. J. DeWitte, L. Pitman, and M. Kluz. 2018. Assessment of digital capacity, needs and access barriers among crop, dairy and livestock producers. American Society of Agricultural and Biological Engineers, Detroit, MI, July 29-Aug. 1, 2018. American Society of Agricultural and Biological Engineers, St. Joseph, MI.

St-Pierre, N. R., and C. S. Thraen. 1999. Animal grouping strategies, sources of variation, and economic factors affecting nutrient balance on dairy farms. J. Animal Sci. 77(Suppl. 2):72-83.

Steeneveld, W., H. Hogeveen, H. W. Barkema, J. van den Broek, and R. B. Huirne. 2008. The influence of cow factors on the incidence of clinical mastitis in dairy cows. J. Dairy Sci. 91:1391-1402. https: //doi.org/10.3168/jds.2007-0705.

Sun, Z., S. Samarasinghe, and J. Jago. 2010. Detection of mastitis and its stage of progression by automatic milking systems using artificial neural networks. J. Dairy Res. 77:168-175. https://doi.org/10 $.1017 /$ S0022029909990550.
Tomic, D., D. Drenjanac, S. Hoermann, and W. Auer. 2015. Experiences with creating a precision dairy farming ontology (DFO) and a knowledge graph for the data integration platform in agriOpenLink. J. Agric. Inform. 6:115-126. https://doi.org/10.17700/ jai.2015.6.4.213.

van der Weerdt, C., and J. de Boer. 2015. Focusing on behaviour to ensure adoption of big data information services in precision livestock farming. Pages 721-729 in Proc. 7th European Conference on Precision Livestock Farming, Milan, Italy. Publications TNO, the Hague, the Netherlands.

Wathes, C. M., H. H. Kristensen, J. M. Aerts, and D. Berckmans. 2008. Is precision livestock farming an engineer's daydream or nightmare, an animal's friend or foe, and a farmer's panacea or pitfall? Comput. Electron. Agric. 64:2-10. https://doi.org/10.1016/j .compag.2008.05.005.

Wolfert, S., L. Ge, C. Verdouw, and M. J. Bogaardt. 2017. Big data in smart farming - A review. Agric. Syst. 153:69-80. https://doi.org/ 10.1016/j.agsy.2017.01.023.

Wu, Y., D. Liang, R. D. Shaver, and V. E. Cabrera. 2019. An income over feed cost nutritional grouping strategy. J. Dairy Sci. 102:4682-4693. 